\title{
La anemia infantil post COVID-19
}

\author{
Anemia in children post COVID-19
}

\author{
Víctor Díaz-Silva ${ }^{1, a}$
}

\section{Sr. Editor:}

Desde el mes de marzo de 2020, el Gobierno peruano declaró el estado de emergencia sanitaria y orden de confinamiento obligatorio debido a la pandemia ocasionada por el SARS-CoV-2. Actualmente, el confinamiento es focalizado en algunas regiones y grupos de riesgo; esta situación ha provocado una crisis en la salud y economía peruana. En tal sentido, se proyecta un aumento en la prevalencia de la anemia infantil como consecuencia de esta crisis.

Los niveles de pobreza aumentarían para este año 2020. Tras el inicio de la pandemia, el Perú presentó una caída de $-3,4 \%$ del Producto Bruto Interno (PBI), y se estima que el desempleo ascendería a $23,6 \%{ }^{(1,2)}$. Esta situación provocará que más peruanos no tengan los recursos suficientes, pese a las medidas económicas planteadas por el Estado.

La alimentación de las familias pobres está siendo afectada por la pandemia. Según el reporte de la Encuesta Nacional remota presentada en la reunión de la Cámara de Exportadores, Logística y Promoción de Inversiones de Santa Cruz (CADEX), realizada en la ciudad de Trujillo 2020, al menos uno de cada cinco peruanos ha tenido menos de dos comidas por día (3). La ingesta de los alimentos ricos en hierro, tales como carne de res y menestras son necesarios para prevenir la anemia. En este escenario es posible que se tenga una alimentación deficiente en hierro en las familias con bajos ingresos.

La situación del estado de emergencia sanitaria ha ocasionado una redirección de los recursos sanitarios afectando a los programas de salud. Muchos establecimientos de salud han dejado de ofrecer sus servicios por personal de salud en licencia o por asignación de recursos a otros establecimientos o por falta de equipos de protección. Por ejemplo, las jornadas de vacunación han sido interrumpidas en muchos países de la región (4). La atención primaria ha dejado de ofrecer sus servicios de prevención y promoción de salud.

Frente a esta situación, el Estado ha elaborado un plan de reactivación en la atención primaria. En la lucha contra la anemia infantil, a partir del mes de mayo se dispone de un plan de intervención sanitaria con participación ciudadana ${ }^{(5)}$. Lamentablemente, el plan aún se encuentra en implementación; por lo que, las medidas de prevención y promoción en la lucha contra la anemia infantil son limitadas.

\footnotetext{
1. Hospital Regional Lambayeque. Lambayeque, Perú.

a. Magíster en Medicina. Especialista en Hematología Clínica.
} 
La lucha contra la anemia infantil tiene muchos frentes que abordar. La desnutrición, el nivel educativo materno deficiente, servicios de salud inaccesibles, la pobreza son factores de riesgo de anemia según un enfoque multidisciplinario; por lo tanto, su abordaje no consiste solamente en la administración de hierro ${ }^{(6)}$. La COVID-19 ha juntado a estos factores de riesgo en un mismo escenario; en consecuencia, la lucha contra la anemia debe afrontarlos integralmente.

La pandemia por la COVID-19 puede aumentar la prevalencia de anemia infantil. El riesgo del incremento en los casos de anemia puede revertirse con las acciones integradas en salud, educación, trabajo y economía. Finalmente, toda crisis genera oportunidades y debemos aprovecharla para fortalecer los primeros niveles de la atención en la salud pública con un enfoque multidisciplinario fomentando la intervención sanitaria con actividades preventivas y promocionales focalizadas en los grupos de riesgo.

Conflictos de interés: El autor declara que no existe conflicto de interés.

Fuentes de inanciamiento: Autofinanciado

\section{REFERENCIAS BIBLIOGRÁFICAS}

1. Reporte de Inflación: junio 2020. Panorama actual y proyecciones macroeconómicas 2020-2021 [Internet]. Banco Central de Reserva del Perú; 2020 [citado 18 de julio de 2020]. Disponible en: https://www.bcrp.gob.pe/docs/ Publicaciones/Reporte-Inflacion/2020/junio/reporte-de-inflacion-junio-2020. pdf

2. Vinelli Ruiz M, Maurer Fossa A. Impacto del COVID-19 en el empleo en el Perú [Internet]. ESAN. 2020 [citado 18 de julio de 2020]. Disponible en: https://www.esan.edu.pe/conexion/actualidad/2020/04/24/impacto-del-covid19-en-el-empleo-en-el-peru/

3. CADEx: "El problema de la anemia en el Perú no es de un solo sector, es de todo el país" [Internet]. Siente Trujillo. 2020 [citado 18 de julio de 2020]. Disponible en: https://sientetrujillo.com/cadex-la-anemia-en-el-peru-no-esproblema-de-un-solo-sector-es-de-todo-el-pais/

4. WHO / Special feature: immunization and COVID-19 [Internet]. WHO. World Health Organization; 2020 [citado 19 de julio de 2020]. Disponible en: http:// www.who.int/immunization/monitoring_surveillance/immunization-and-covid-19/en/

5. Directiva Sanitaria que establece las disposiciones para garantizar las prestaciones de prevención y control de la anemia en el contexto de la COVID-19. RM 275-2020-MINSA. Documentos Normativos MINSA y Decretos de Salud en Contexto COVID-19; 2020.

6. Falivene M, Fattore G. Abordaje multidimensional de la anemia por de ciencia de hierro en niños menores de dos años de edad del Noreste Argentino. Años 2004-2005. Arch Argent Pediatr [Internet]. Febrero de 2016 [citado 17 de julio de 2020];114(1). Disponible en: http://www.sap.org.ar/docs/publicaciones/archivosarg/2016/v114n1a04.pdf 